\title{
Prescriptions Written in Capital Letters in Compliance with National Accreditation Board of Hospital Standards
}

\author{
${ }^{1}$ Saakshi Kaushik, ${ }^{2}$ Ritwik Chawla, ${ }^{3}$ Shalini Bhalla
}

\section{ABSTRACT}

Objectives: (1) To study compliance rate of prescriptions written in capital letters according to continual quality improvement (CQI) $3 \mathrm{j}$ indicator of National Accreditation Board of Hospital (NABH) (4th edition). (2) To study compliance to doctors and patient detail, legibility of prescriptions, strength and dose, frequency, route of administration, dosage form, abbreviation for drug, allergy detail, and leading zeros in the dose.

Materials and methods: Convenient randomly selected Medication Administration Record (MAR) sheets from wards and intensive care units (ICUs) were studied. One hundred thirty-two prescriptions were identified for errors pertaining to doctor's details, patient's details, and medication details. Errors were captured on a prepared checklist for a period of 11 days. Results were analyzed by Microsoft Excel.

Results: Results were expressed in percentages for wards and ICUs respectively. Six hundred twenty four and 652 drugs were observed in wards and ICUs respectively. Doctor's name was present in 79.6 and $83.3 \%$. Out of 55 prescriptions in both wards and ICUs, patient's name compliance was 94.5 and $96.4 \%$ and patient's weight was 83.6 and $81.8 \%$ respectively. Compliance for drugs in capital was 98 and $100 \%$ for wards and ICUs respectively. Details pertaining to medication were also found out subsequently on various parameters.

Conclusion: The study revealed that the level of completeness of handwritten prescriptions was low in terms of doctor's details and patient's weight, which indicates unsatisfactory commitment of the prescribers to follow the hospital guidelines of prescribing. Majority of prescriptions showed compliance to medication written in capital but still the compliance to clear and legible prescriptions is three-fourths of the total prescriptions.

Keywords: Accreditation, Compliance, Medication administration record, NABH, Prescriptions, Quality.

How to cite this article: Kaushik S, Chawla R, Bhalla S. Prescriptions Written in Capital Letters in Compliance with National Accreditation Board of Hospital Standards. Int J Res Foundation Hosp Healthc Adm 2016;4(2):89-99.

Source of support: Nil

Conflict of interest: None

\footnotetext{
${ }^{1,2}$ Intern, ${ }^{3}$ Medical Superintendent

1,2 Indian Institute of Health Management Research University Jaipur, Rajasthan, India

${ }^{3}$ Fortis Flt. Lt. Rajan Dhall Hospital, New Delhi, India

Corresponding Author: Saakshi Kaushik, Intern, Indian Institute of Health Management Research University, Jaipur Rajasthan, India, e-mail: sakshik334@gmail.com
}

\section{BACKGROUND}

Prescription writing is one of the most important and basic skill that a doctor needs. It was seen in previous studies where a large number of medical errors include medication errors, which may be related to writing of an illegible prescription and dispensing of wrong, inappropriate medications that results in adverse events and death. ${ }^{1}$ Prescription errors account for $70 \%$ of medication errors. $^{2}$ Studies show that the range of errors attributable to junior doctors, who are responsible for most prescriptions in hospitals, can vary from 2 to 514 per 1000 prescriptions and from 4.2 to $82 \%$ of patients or charts reviewed. ${ }^{3}$ Further studies, in which legibility of doctors' handwriting was assessed, revealed that doctors' handwriting when compared to other health care professional and administrators was the worst of all. ${ }^{4}$ A study by Rayan et al suggested that the errors of prescribing are the most common form of avoidable medication errors; these need to be targeted and improved. ${ }^{5}$ As per the 'Right to Information Act 2005' (RTI Act 2005), it is the inherent right of every patient to have a correct and clear prescription. ${ }^{1}$ After the introduction of Consumer Protection Act 1986 (CPA-1986) in India, prescription has become a valuable, consumable linkage between the patient and the registered medical practitioner and it is also the ethical and legal duty of medical practitioner to write the prescription clearly and legibly, which are the essential features of every prescription. ${ }^{6}$ A public notice by the Ministry of Health and Family Welfare (MoHFW) proposes a change in the Indian Medical Council (IMC) regulation. Union Health Minister, JP Nadda agreed that illegible prescription by doctors may lead to serious implications and even death in certain cases. Later, he approved the amendment to the Indian Medical Council Regulations, 2002, providing therein that every physician should prescribe drugs with generic names in legible and capital letters and they should ensure that there is a rational prescription and use of drugs.?

Unfortunately, there is less awareness and recording of adverse drug reactions and medication errors in India and very few physicians are following prescription guidelines. To improve the quality of life, it is very important to standardize the prescription at all levels of the health care delivery system. Various prescription audit has to be conducted, to seek observation, evaluation, and further 
recommendation on the prescribing practices of medical practitioners to make rational prescribing. ${ }^{8}$

\section{INTRODUCTION}

Prescription is a written directive, as for the compounding or dispensing and administration of drugs, or for other service to a particular patient. There are four parts to a drug prescription:

1. Superscription: Consisting of the word recipe, take, or its sign, $\mathrm{Rx}$

2. Inscription: The main part of the prescription containing the names and dosage of the drugs

3. Subscription: Directions for mixing the ingredients and designation of the form (pill, powder, solution, etc.) in which the drug is to be made.

4. Signature: Directions to the patient regarding the dose and times, etc., of taking the remedy, preceded by the word signa, designate, or its abbreviation, S. or Sig., ${ }^{9} 10$

The Medication Use Process is commonly divided into four stages:

1. The prescribing stage (writing/ordering the prescription)

2. The medication supply stage

3. The administration stage (administering the prescription)

4. The monitoring stage (counseling the patient about the prescription and monitoring treatment outcome). ${ }^{11}$

Prescription writing error (prescription errors, including illegibility) and administering errors are the two most frequent types of medication errors. Prevention of errors at the prescribing stage is one of the most important step toward reducing medication errors and it has been recognized as a priority in health care systems worldwide. ${ }^{12}$ The experts conclude that ambiguity or confusion in prescription order may be avoided in the beginning itself, by following some principles in prescribing stage. At the time of prescribing, always make sure that the prescription is legible and easy to read, complete doctor and patient details must be clearly mentioned, all text must be in clear handwriting and should be written in capital and all details pertaining to a drug must be mentioned clearly. Abbreviation of medicine name, archaic terminologies, such as Q.D. or O.D should be avoided. ${ }^{1}$ We are identifying the number of prescriptions complying with the prescription guideline pattern, laid down by the hospital in which the study was conducted. In that hospital, certain policies and procedures have been established. As per those policies, certain criteria must be followed while writing a prescription in an inpatient department, to avoid medical errors.

- Patient information: It is used in a prescription to individualize treatment plan and to avoid confusion; hence, it is mandatory to write the patient demographics like name, age, sex, address, identification number, and weight. It is also compulsory to fill allergy box to know the allergic status before prescribing the drugs.

- Prescriber's information: Only a registered medical practitioner-medical officer, senior medical officer, and consultant shall prescribe medications. It is mandatory to prescribe all drugs with physician name and sign. So, when there is any doubt regarding the drugs and follow-up, contact physician directly.

- Drug information: Drugs are available in different dosage forms and strengths, so it is mandatory for every doctor to write the drug name in capital letters, clearly mentioning all the required details (frequency, dosage form, route, strength, time) without any unaccepted abbreviations and overwriting. Leading zero should always be used (e.g., $0.1 \mathrm{mg}$ ) and avoid using trailing zero (e.g., $1.0 \mathrm{mg}$ ). When medication is needed to be discontinued the word "discontinue" must be mentioned.

- Legibility: Make sure that your prescription is legible and easy to read. Due to illegible handwriting, nurses get confused and dispense look-alike drugs to patient. It has been found that this is the most common error identifying from practitioners. ${ }^{8,13}$ Illegible prescriptions result in a lower quality of health care by loss of time and money, medication errors and patient harm, inefficient or faulty communications, and create legal issues. $^{14}$

The National Accreditation Board for Hospital (NABH) and health care provider has certain accreditation standards for hospitals on particulars of continual quality improvement (CQI). The organization must identify key indicators to monitor the clinical structures, processes, and outcomes, which are used as tools for continual improvement. One of the objective elements is patient safety goals. Hence, the goal of this study is to capture the compliance of medication prescriptions written in capital and their legibility.

\section{OBJECTIVES}

- To study compliance rate of prescriptions written in capital letters according to CQI $3 \mathrm{j}$ indicator of $\mathrm{NABH}$ (4th edition).

- To study compliance to doctors and patient detail, legibility of prescriptions, strength and dose, frequency, route of administration, dosage form, abbreviation for drug, allergy detail, and leading zeros in the dose.

\section{PURPOSE}

The hospital is presently running in its 3rd cycle, and NABH mandates institutionalization of the revised standards (4th edition) by 1st July. One of the CQI 3 j indicator 
"Compliance to medication prescription in capitals" will be reviewed in the study as was asked by the medical superintendent of the hospital.

\section{SCOPE OF THE STUDY}

Study the Medication Administration Records (MARs) compliance to documentation standards as per $\mathrm{NABH}$ policy in wards and intensive care units (ICUs) and study the drug chart of pediatric and neonatal intensive care units (NICU).

\section{MATERIALS AND METHODS}

\section{Study Area}

Convenient randomly selected MAR sheets from wards and ICUs were studied.

\section{Study Design}

Retrospective descriptive observational study.

\section{Sample Design}

In this study, convenient random sampling technique will be used to select medical prescriptions (MAR) from the inpatient department (wards and ICU) during the functional hours.

\section{Study Time}

Various MAR sheets from existing one month of hospital data were observed and the required data was recorded over a period of 11 days from April 13, 2016 to April 25, 2016.

\section{Study Tool}

Prepared checklist (Annexure 1). Microsoft Excel for analysis of data.

\section{METHOD OF MEASUREMENT}

A sample of 132 prescriptions were selected during the month of April 2016 to identify prescription errors pertaining to doctor's details, patient's details, and medication details. Compliance rate of prescriptions written in capital and its legibility have been identified. Prescriptions were observed based on the presence or absence of the understated details. Various parameters were identified in each prescription, which are as follows:

- Doctors name and signature

- Patient name, age, sex, ID number, weight, date of admission.

- Drugs name written in capital

- Strength and dose of drug

- Frequency of drug
- Route of administration

- Dosage form of drug

- Abbreviation for drug name

- Leading zero

- Allergy details

- Data for stat/once only/premedication drugs (in capital, overwriting, not signed within 24 hours)

- Legibility of prescriptions was assessed based on the following points:

- Point 1: Prescription details are clear and legible.

- Point 2: Prescription details are clear but require efforts to read.

- Point 3: Prescription details are not at all clear.

- Legibility of drugs was assessed base on the following points:

- Point 4: One drug name is not clear.

- Point 5: More than one drug name is not clear.

- Point 6: All drugs names are clear.

During this study, over a period of 11 days, five prescriptions were randomly observed every day from both, ward and ICU, to calculate the compliance of prescription in six different wings of wards and in five different ICUs. (In the hospital two floors were occupied as wards, and each floor was named as " $\mathrm{A}$ " and " $\mathrm{B}$ " with three wings on each floor namely A1, A2, A3, B1, B2, B3.) Every day, two prescriptions were also observed separately from pediatric ICU (PICU) and NICU, to capture leading zeros.

\section{Inclusion Criteria}

- Inpatient department prescriptions (wards and ICUs)

- MAR sheet (Annexure 2 and 3)

- Medication chart for PICU and NICU (Annexure 4)

\section{Exclusion Criteria}

- Outpatient department prescriptions

- Some data of prescription like (generic name of drug, use of archaic terminologies, spellings of drugs, time and date of dosage, word "discontinued "mentioned or not) were excluded from study.

- Accuracy of prescriptions

- Doctor progress report

\section{RESULTS}

A total of 132 prescriptions of wards and ICUs were taken for observation for compliance rate of drugs written in capital and its legibility (Annexure 1, Tables 1 and 2; Graphs 1 to 8 ).

Results were expressed in percentages for wards and ICUs respectively. Lacking with the physician's information is one of the drawbacks that may create a chance for medical errors. In this study, when 624 and 652 drugs was 
Table 1: Compliance related to patient and doctor's details in wards and ICU

\begin{tabular}{|c|c|c|c|}
\hline \multicolumn{4}{|c|}{ Details pertaining to patient } \\
\hline Criteria & Total & $\begin{array}{l}\text { Compliance } \\
\text { of ward (\%) }\end{array}$ & $\begin{array}{l}\text { Compliance } \\
\text { of ICU (\%) }\end{array}$ \\
\hline Patient name & $\mathrm{n}=55$ & 94.5 & 96.4 \\
\hline Patient age and sex & $\mathrm{n}=55$ & 100.0 & 100.0 \\
\hline Patient ID number & $n=55$ & 100.0 & 100.0 \\
\hline Patient weight & $n=55$ & 83.6 & 81.8 \\
\hline Date of admission & $\mathrm{n}=55$ & 100.0 & 100.0 \\
\hline \multicolumn{4}{|c|}{ Details pertaining to doctor } \\
\hline Doctor's name present & $\begin{array}{l}\mathrm{N}_{\mathrm{w}}=624 \\
\mathrm{~N}_{\mathrm{i}}=652\end{array}$ & 79.6 & 83.3 \\
\hline Doctor's signature present & $\begin{array}{l}N_{w}=624 \\
N_{i}=652\end{array}$ & 92.3 & 96.3 \\
\hline
\end{tabular}

$\mathrm{n}$ : Number of prescriptions observe, each in ward and ICU; $\mathrm{N}_{\mathrm{w}}$ : Number of drugs observed in wards; $\mathrm{N}_{\mathrm{i}}$ : Number of drugs observed in ICU

observed in wards and ICUs respectively, doctor's name was present in 79.6 and $83.3 \%$, whereas signatures were present in 92.3 and $96.3 \%$ (Annexure 1, Table 1 and Graph 1). Patient information is used to individualize treatment plan and to avoid confusion among patients. When 110 prescriptions were observed, it was found that there was $100 \%$ compliance for patient's age, sex, ID number, date of admission, however, compliance for patient's name was 94.5 and $96.4 \%$ and patient's weight was 83.6 and $81.8 \%$ (Annexure 1, Table 1 and Graph 2).

In order to get information about the , prescriptions were observed and it was found that compliance for strength of drug mention is 89.7 and $93.7 \%$, whereas dose was mentioned in 93.4 and $97.1 \%$. Allergy details were mentioned in 98.4 and $97.2 \%$. In 98.4 and $99.7 \%$, frequency of drug was mentioned, whereas for route of administration and dosage form it was (93.3 and 97.1\%) and (96.2 and 98.9\%) respectively (Annexure 1, Table 2 and Graph 3).

In the same number of prescriptions, it was also observed that out of 164 drugs in wards and 212 drugs
Table 2: Compliance related to medication details

\begin{tabular}{llll}
\hline \multicolumn{4}{c}{ Details pertaining to medication } \\
\hline Criteria & Total & $\begin{array}{l}\text { Compliance } \\
\text { of ward (\%) }\end{array}$ & $\begin{array}{l}\text { Compliance } \\
\text { of ICU (\%) }\end{array}$ \\
\hline Drugs written in capital & $\mathrm{N}_{\mathrm{w}}=624$ & 98 & 100 \\
& $\mathrm{~N}_{\mathrm{i}}=652$ & \\
Strength of drug & $\mathrm{N}_{\mathrm{w}}=624$ & 89.7 & 93.7 \\
mentioned & $\mathrm{N}_{\mathrm{i}}=652$ & \\
Dose of drug mentioned & $\mathrm{N}_{\mathrm{w}}=624$ & 93.4 & 97.1 \\
& $\mathrm{~N}_{\mathrm{i}}=652$ & \\
Frequency of drug & $\mathrm{N}_{\mathrm{w}}=624$ & 98.4 & 99.7 \\
mentioned & $\mathrm{N}_{\mathrm{i}}=652$ & \\
Route of administration & $\mathrm{N}_{\mathrm{w}}=624$ & 93.3 & 97.1 \\
mentioned & $\mathrm{N}_{\mathrm{i}}=652$ & \\
Dosage form of & $\mathrm{N}_{\mathrm{w}}=624$ & 96.2 & 98.90 \\
medication mentioned & $\mathrm{N}_{\mathrm{i}}=652$ & & \\
Abbreviation for drug & $\mathrm{N}_{\mathrm{w}}=624$ & 97.3 & 97.0 \\
name not mentioned & $\mathrm{N}_{\mathrm{i}}=652$ & & \\
Allergy details mentioned & $\mathrm{N}_{\mathrm{w}}=624$ & 98.4 & 97.2 \\
& $\mathrm{~N}_{\mathrm{i}}=652$ & & \\
Stat drugs in capital & $\mathrm{N}_{\mathrm{w}}=164$ & 49.3 & 95.8 \\
(by nurses) & $\mathrm{N}_{\mathrm{i}}=212$ & & \\
No overwriting in & $\mathrm{N}_{\mathrm{w}}=164$ & 100.0 & 100.0 \\
stat drug & $\mathrm{N}_{\mathrm{i}}=212$ & & \\
Signed within 24 hours & $\mathrm{N}_{\mathrm{w}}=164$ & 83.5 & 92.9 \\
& $\mathrm{~N}_{\mathrm{i}}=212$ & & \\
& & &
\end{tabular}

Legibility of prescriptions

scoring

Point 1

Point 2

$\begin{array}{ll}\mathrm{n}=55 & 61.8 \\ \mathrm{n}=55 & 38.2 \\ \mathrm{n}=55 & 0.0\end{array}$

70.9

Point 3

$n=55$

0.0

29.1

0.0

Legibility of drugs name scoring

Point 4

Point 5

Point 6

$\begin{array}{ll}\mathrm{n}=55 & 23.6 \\ \mathrm{n}=55 & 16.4 \\ \mathrm{n}=55 & 60.0\end{array}$

Pediatric ICU and

Neonatal ICU

Leading zeros present in $\mathrm{N}=74 \quad-$

99.0

$\mathrm{n}$ : Number of prescriptions observe, each in ward and ICU; $\mathrm{N}_{\mathrm{w}}$ : Number of drugs observed in wards; $\mathrm{N}_{\mathrm{i}}$ : Number of drugs observed in ICU; N: Number of drugs in PICU and NICU

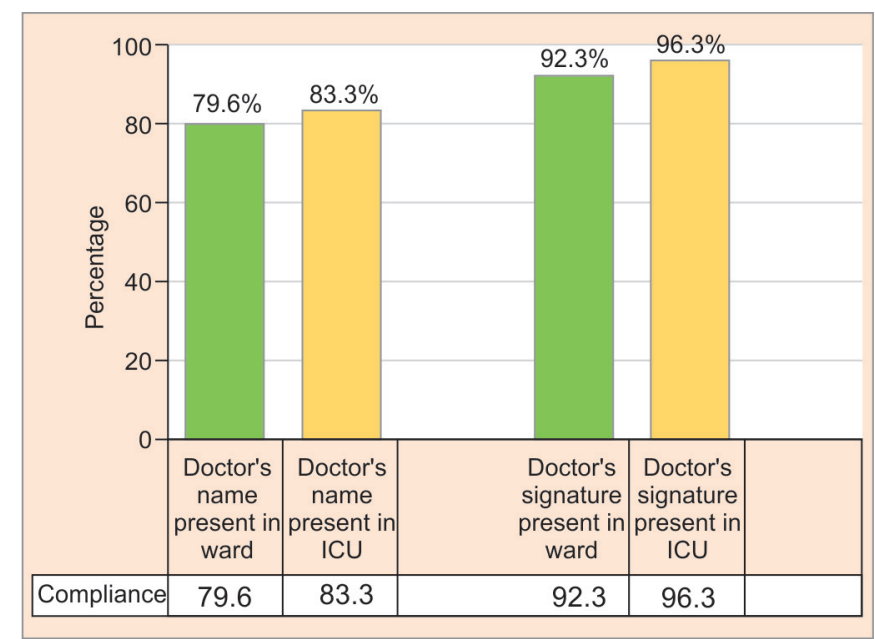

Graph 1: Compliance of doctor's details

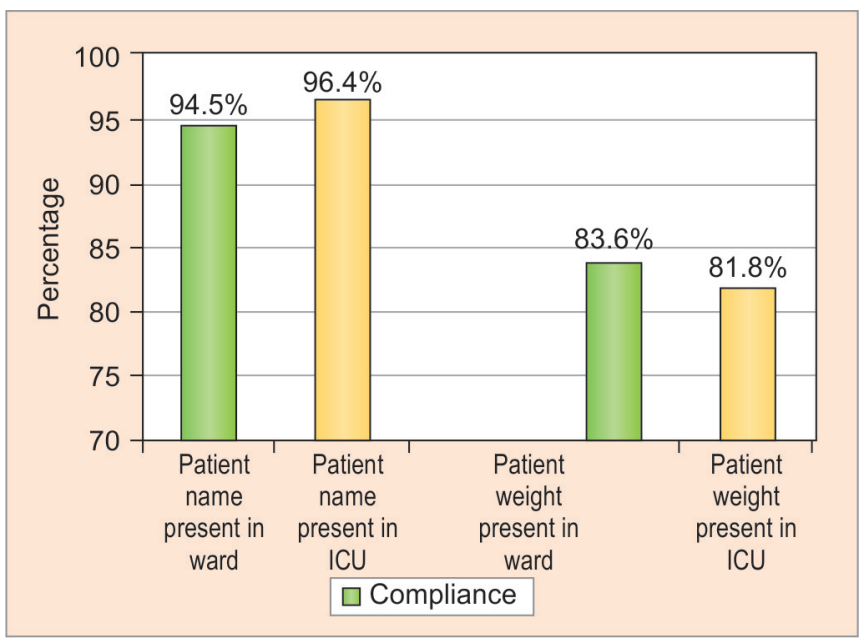

Graph 2: Compliance of patient's details 


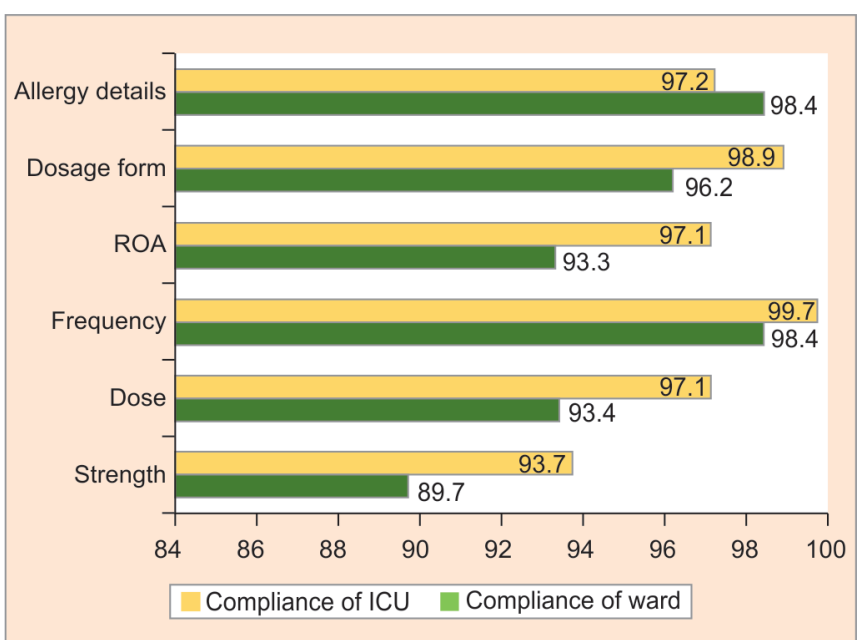

Graph 3: Compliance of medication details

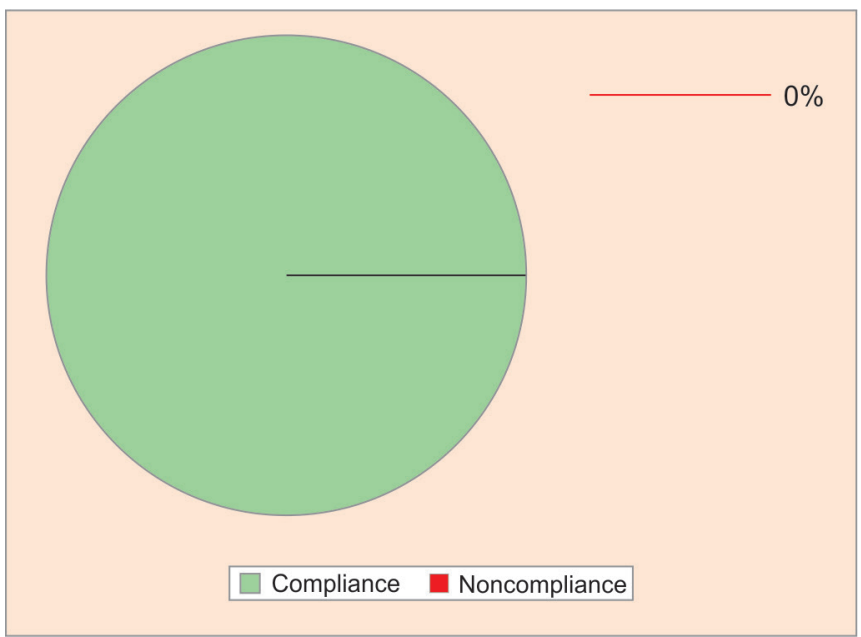

Graph 5: Compliance of drug in capital in icu

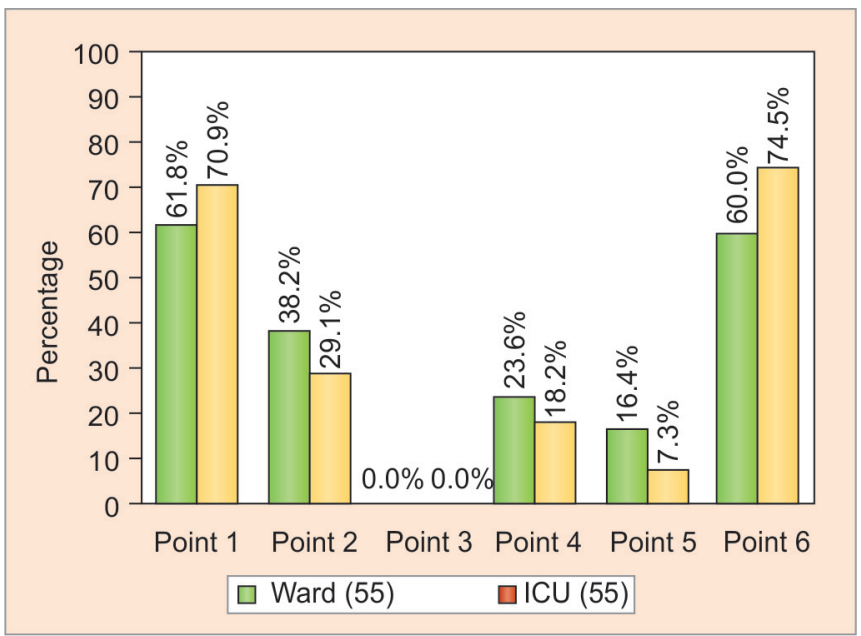

Graph 7: Legibility of prescription and drug name

in ICU for stat/once only/premedication, compliance for drugs in capital and stat not signed within 24 hours were (49.3 and $95.8 \%)$ and ( 83.5 and $92.9 \%$ ) respectively. (Annexure 1, Table 2 and Graph 6).

In the prescriptions 98 and $100 \%$ of the drugs were written in capital letters (Annexure 1, Table 2 and Graphs 4, and 5).

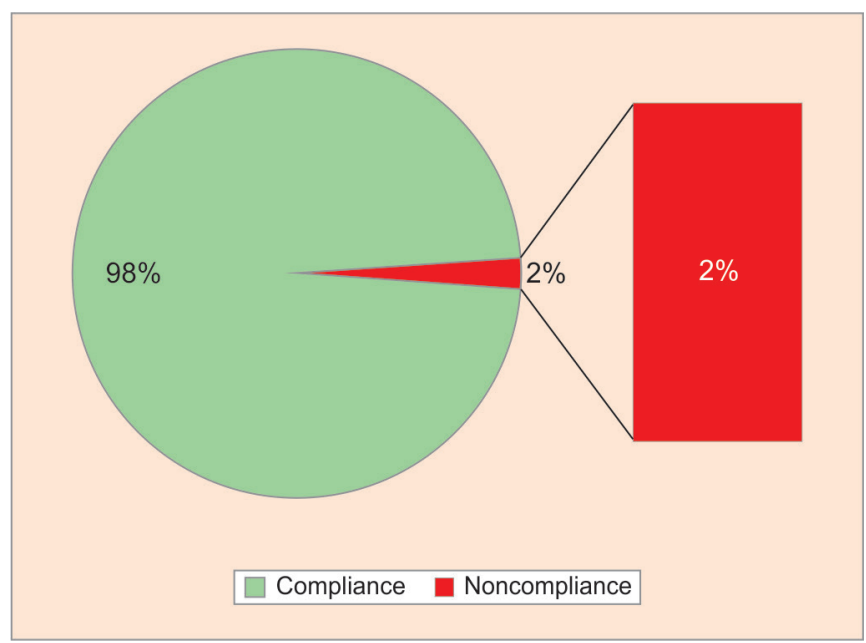

Graph 4: Compliance of drus in capital in ward

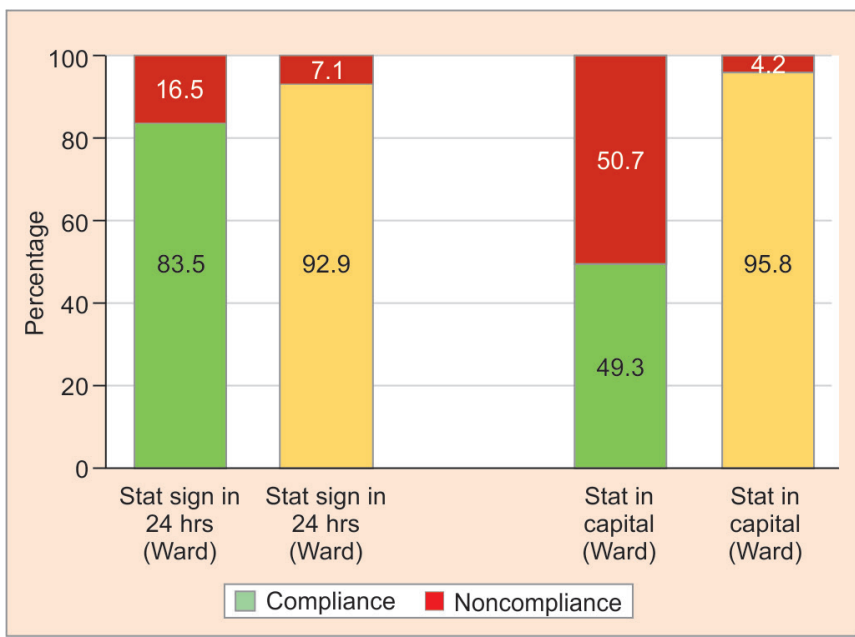

Graph 6: Stat/once only/premedication chart

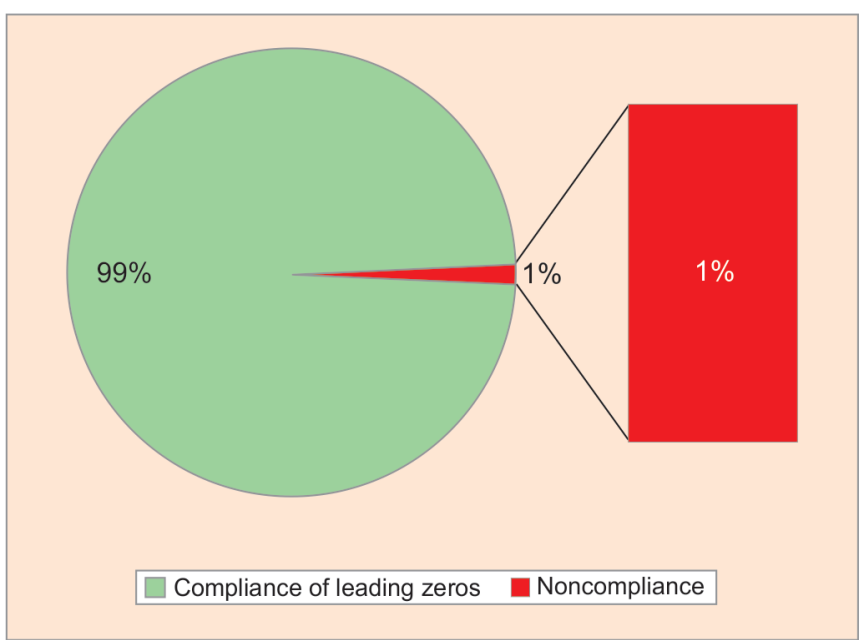

Graph 8: Compliance for leading zeros

Out of 74 drugs of PICU and NICU, 99\% have correctly placed leading zeros (Annexure 1, Table 2 and Graph 8).

When legibility of prescriptions was observed, none of the prescription was not at all clear (point 3). About 61.8 and $70.9 \%$ of prescriptions were legible (point 1 ) and rests 38.2 and $29.1 \%$ were clear but requires effort to read 
(point 2). When legibility for drug names was observed, in 23.6 and $18.2 \%$ of prescription one drug name is not clear (point 4), in 16.4 and $7.3 \%$ prescription more than one drug is not clear, rest of prescription, i.e., 60 and $74.5 \%$ all drug names are clear (Annexure 1, Table 2 and Graph 7).

\section{LIMITATIONS}

- Due to time constraint, our sample size was not adequate as per the required standard sample size set by $\mathrm{NABH}$ and health care providers. This study can also be conducted with a large sample size and for a longer duration and perhaps the result can then be generalized. (For 1000 screening population, NABH recommends 278 sample size.) (Annexure 5)

- Other limitations also include study exclusion criteria.

- Outpatient department prescriptions

- Some data of prescription like (generic name of drug, use of archaic terminologies, spellings of drugs, time and date of dosage, word "discontinued "mentioned or not) were excluded from study.

- Accuracy of prescriptions

- Doctor progress report

\section{CONCLUSION}

The study revealed that the level of completeness of handwritten prescriptions was low in terms of doctor's details and patient's weight, which indicates unsatisfactory commitment of the prescribers to follow the hospital guidelines of prescribing. Remaining compliances showed less discrepancy. Majority of prescriptions showed compliance to medication written in capitals but still the compliance to clear and legible prescriptions is only three-fourths of the total prescriptions.

\section{RECOMMENDATIONS}

- Various studies have shown that electronic prescribing can reduce the incidence of medication error by more than $50 \%$ and improve the quality of life and patient safety. ${ }^{15}$ So there is a need to move toward electronic prescribing to allow the hospital immediate benefit of improving legibility, completeness, and elimination of transcription errors.

- Additional research studies must be conducted in the hospital as per the NABH sample size, to assess the prescribing practices of practitioners on their prescription.

- The study highlights the need of more training programs and regular assessments to train and sensitize the prescriber about prescribing skills and the importance of neglected criteria. Also encourage them to follow the hospital prescription guidelines to make $100 \%$ compliance for the upcoming CQI $3 \mathrm{j}$ indicator of NABH.

- After implementation of e-prescriptions, studies can be conducted to compare them to handwritten prescriptions.

\section{ANNEXURE 1}

Table 1: Checklist

\begin{tabular}{lll}
\hline & \multicolumn{1}{c}{ Details pertaining to doctors } \\
\hline Sl. no. & Identification criteria & Response \\
\hline (a) & Doctor's name written on the prescription & Total \\
(b) & Doctor's signature & No name \\
& & Present \\
\hline
\end{tabular}

SI. no. Identification criteria

(a)

(b)

(c)

(d)

(e)
Patient's full name

Patient's age and sex

Patient's ID number

Patient's weight

Date of admission

Response

Present

Absent

Present

Absent

Present

Absent

Present

Absent

Present

Absent 
Table 2: Details pertaining to medications

SI. no. Identification criteria

Response

(a) Name of drug written legibly

Legibility of prescriptions was assessed on the basis of the following points:

- Point 1: Prescription details are clear and legible

Point 1

- Point 2: Clear but requires effort to read

Point 2

- Point 3: Prescription details not at all clear

Point 3

Legibility of drug name was assessed on the basis of the following points:

- Point 4: One drug name is not clear

Point 4

- Point 5: More than one drug name is not clear

Point 5

- Point 6: All drug names are clear

Point 6

(b) Name of drug written in CAPITAL

No. of drugs prescribed

No. of drugs not written in capital

(c) Strength and dose of the prescribed drugs not mentioned

Not mentioned strength

Dose

(d) Is the frequency of drugs prescribed mentioned?

Not present

(e) Is the route of administration of the prescribed drugs mentioned

Not present

(f) Is the dosage form of the medications mentioned

Not present

(g) Abbreviation for drug name used in the prescription

Present

(h) Use of leading zeros in dose of the drug used

Present

(i) Stat/once only/premedication drugs consultations signed by the consulting doctor within 24 hours or not

No. of drugs

Drugs not in capital

Overwriting present

Not signed in 24 hours

(j) Allergy details mentioned

Present

Absent 


\section{ANNEXURE 2}

Patient's Name :

UHID :

IPID :

Age :

Sex :

D.O.A.

Unit :

\section{MEDICATION ADMINISTRATION RECORD}

\begin{tabular}{|l|l|l|}
\hline $\begin{array}{l}\text { Previous Hospitalization } \\
\text { Yes } \square \text { No } \square\end{array}$ & Weight in $\mathrm{kg}$ & Special Diet \\
\hline Blood Group: & Diagnosis: \\
\hline Drug Hypersensitivities/Allergies: & $\begin{array}{l}\text { Surgery/ Procedure: } \\
\text { Date of Surgery: }\end{array}$ \\
\hline \multicolumn{2}{|l|}{} \\
\hline
\end{tabular}

Standard Timings :Once a day : 10am, Twice a day :10am - 10pm,

:Four times a day : $12-6-12-6, Q 8 \mathrm{Hrly}: 6 \mathrm{am}-2 \mathrm{pm}-10 \mathrm{pm} \quad$ Key: $\mathrm{WH}=$ Withheld

Note : Actual timings may vary as per ward routine. Administration of drugs half-an-hour before and after is acceptable

\begin{tabular}{|c|c|c|c|c|c|c|c|c|c|c|}
\hline \multirow[t]{2}{*}{ DRUG } & \multirow[t]{2}{*}{ Generic Name } & Date & & & & & & & & \\
\hline & & Time & Time & Inital & Time Initia & Time & Initia & Time & Inital & Time Initial \\
\hline \multicolumn{2}{|l|}{ Special Instructions } & & & & & & & & & \\
\hline Dose & Freq & & & & & & & & & \\
\hline Doctor's Name & Signature & & & & & 7 & & & & \\
\hline
\end{tabular}

\begin{tabular}{|c|c|c|c|c|c|c|c|c|c|c|c|}
\hline \multirow[t]{2}{*}{ DRUG } & \multirow[t]{2}{*}{ Generic Name } & Date & & & & & & & & & \\
\hline & & Time & Time & Inita & Time & Initia! & Time & Initia & Time & Inital & Time Initial \\
\hline \multicolumn{2}{|l|}{ Special Instructions } & & & & & & & 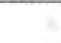 & & & \\
\hline Dose & Freq & & & & & & & 4 & & & \\
\hline Doctor's Name & Signature & & & & & & & & & & \\
\hline
\end{tabular}

\begin{tabular}{|c|c|c|c|c|c|c|c|c|c|}
\hline \multirow[t]{2}{*}{ DRUG } & \multirow[t]{2}{*}{ Generic Name } & Date & & & & & & & \\
\hline & & Time & Time Inital & Time Initial & Time & Initial & Time & Inital & Time Initial \\
\hline Special Instructions & Route & & & & & & & & \\
\hline Dose & Freq & & & & & & & & \\
\hline Doctor's Name & Signature & & & & & & & & \\
\hline
\end{tabular}

All Drug Names Will Be Written In Capital Letters By Doctor 


\section{ANNEXURE 3}

As Required Prescriptions

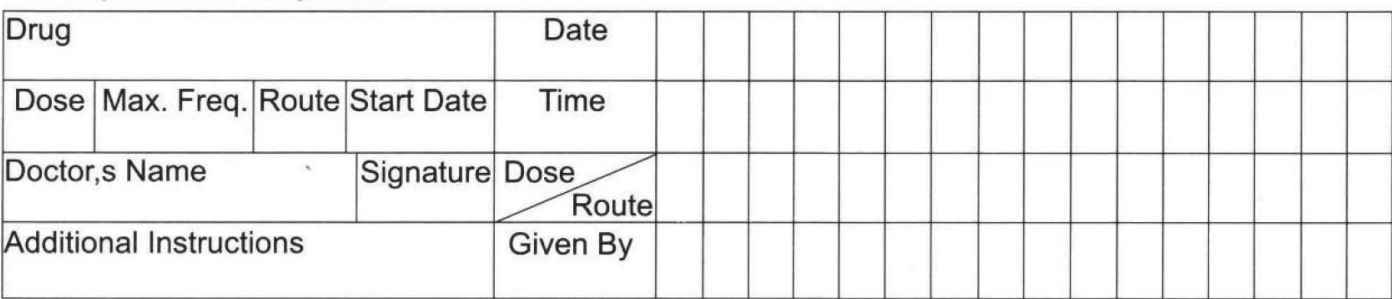

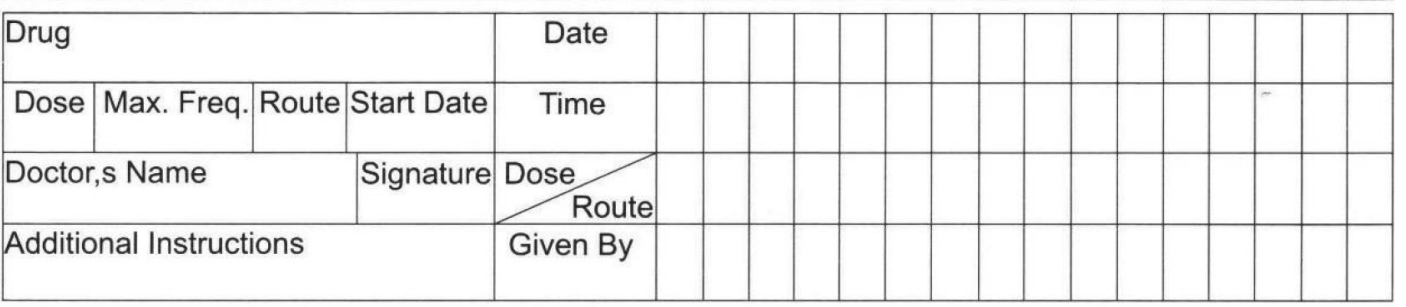

Record of Drugs Not administered or Withheld

\begin{tabular}{|l|l|l|l|l|l|}
\hline Date & Time & Name of Drug & Reason Not Administered & Ordered By Doctor & Nurse Initial \\
\hline & & & & & \\
\hline & & & & & \\
\hline & & & & & \\
\hline & & & & & \\
\hline & & & & & \\
\hline & & & & & \\
\hline & & & & & \\
\hline
\end{tabular}

Stat / Once Only / Premedication Drugs

\begin{tabular}{|l|l|l|l|l|l|l|l|}
\hline Date & Drug (Approved Name) & Dose & Time & Route & $\begin{array}{c}\text { Doctor's } \\
\text { Signature }\end{array}$ & $\begin{array}{c}\text { Given By } \\
\text { by I / C }\end{array}$ \\
\hline & & & & & & & \\
\hline & & & & & & & \\
\hline & & & & & & & \\
\hline & & & & & & & \\
\hline & & & & & & & \\
\hline & & & & & & & \\
\hline
\end{tabular}

\begin{tabular}{|l|l|l|l|l|l|l|l|l|l|}
\hline Date & Shift & $\begin{array}{c}\text { Name of Nurse } \\
\text { (in capitals) }\end{array}$ & $\begin{array}{c}\text { Emp. } \\
\text { Id. }\end{array}$ & Initials & Date & Shift & $\begin{array}{c}\text { Name of Nurse } \\
\text { (in capitals }\end{array}$ & $\begin{array}{c}\text { Emp. } \\
\text { Id. }\end{array}$ & Initials \\
\hline & & & & & & & & \\
\hline & & & & & & & & \\
\hline & & & & & & & & & \\
\hline & & & & & & & & \\
\hline & & & & & & & & & \\
\hline & & & & & & & & \\
\hline & & & & & & & & \\
\hline & & & & & & & & & \\
\hline
\end{tabular}

All Drug Names Will Be Written In capital Letters By Doctor 
ANNEXURE 4

\begin{tabular}{|c|c|c|c|c|c|c|c|}
\hline \multicolumn{8}{|c|}{ TREATMENT CHART } \\
\hline \multirow[t]{2}{*}{ S.No. } & Drug \& Dose & \multicolumn{5}{|c|}{ Time } & \multirow[t]{2}{*}{ VOL. IN 24 hrs } \\
\hline & ANTIBIOTICS & 08:00 & $12: 00$ & 16:00 & 20:00 & 24:00 & \\
\hline \multicolumn{8}{|l|}{1} \\
\hline \multicolumn{8}{|l|}{2} \\
\hline \multicolumn{8}{|l|}{3} \\
\hline \multicolumn{8}{|l|}{4} \\
\hline \multicolumn{8}{|l|}{5} \\
\hline \multicolumn{8}{|l|}{6} \\
\hline & IONOTROPES & & & 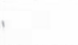 & & & \\
\hline \multicolumn{8}{|l|}{1} \\
\hline 2 & & & & & & & \\
\hline \multicolumn{8}{|l|}{3} \\
\hline \multicolumn{8}{|l|}{4} \\
\hline \multicolumn{8}{|l|}{5} \\
\hline & SEDATION ANALGESIA/ PARALYSIS & & & & & & \\
\hline \multicolumn{8}{|l|}{1} \\
\hline \multicolumn{8}{|l|}{2} \\
\hline \multicolumn{8}{|l|}{3} \\
\hline \multicolumn{8}{|l|}{4} \\
\hline & OTHERS INCLUDING I.V. FLUIDS & & & & & & \\
\hline \multicolumn{8}{|l|}{1} \\
\hline \multicolumn{8}{|l|}{2} \\
\hline \multicolumn{8}{|l|}{3} \\
\hline \multicolumn{8}{|l|}{4} \\
\hline \multicolumn{8}{|l|}{5} \\
\hline \multicolumn{8}{|l|}{6} \\
\hline 7 & & & & & & & \\
\hline
\end{tabular}


ANNEXURE 5

\begin{tabular}{ll}
\hline \multicolumn{2}{c}{ C. Sample size annexure } \\
\hline Screening population & Sample size \\
\hline 50 & 44 \\
100 & 79 \\
150 & 108 \\
200 & 132 \\
500 & 217 \\
1000 & 278 \\
2000 & 322 \\
5000 & 357 \\
10000 & 370 \\
20000 & 377 \\
\hline *For the recommended sample size, all the samples should \\
be taken on continuous basis; Sample size recommended by \\
NABH (4th edition) for capturing CQI 3j indicator
\end{tabular}

\section{REFERENCES}

1. Buxton, Iain LO. Principles of prescription order writing and patient compliance. Goodman and Gilman's the pharmacological basis of therapeutics. Ed. Laurence L. Brunton, John S. Lazo, and Keith L. Parker. 11th ed. New York: McGraw-Hill, 2006. 1777-786. Print

2. Dean Franklin B, Vincent C, Schachter M, Barber N. The incidence of prescribing errors in hospital inpatients: an overview of the research methods. Drug Saf 2005;28(10):891-900.

3. Ross S, Bond C, Rothnie H, Thomas S, Macleod MJ. What is the scale of prescribing errors committed by junior doctors? A systematic review. Br JClin Pharmacol 2009 Jun;67(6):629-640.

4. Lyons R, Payne C, McCabe M, Fielder C. Legibility of doctors' handwriting: quantitative comparative study. BMJ 1998 Sep;317(7162):863-864.

5. Rayan et al. (2016). Medication And Prescribing Errors Encountered In Khartoum Dental Hospital. World Journal of Pharmacy and Pharmaceutical Sciences, 4(10), 294309. Retrieved from http://www.wjpps.com/download/ article/1443596165.pdf.

6. Vries, T., Henning, R., Hogerzeil, H., \& Fresle, D. (2016). Guide to Good Prescribing: A practical Manual (1st ed., p. 52). Geneva: World health Organization.
7. Health Ministry to Ask Doctors to Write Prescriptions in Capital Letters." The Times of India. PTI, 11 June 2015. Web. 23 Apr. 2016. Retrieved from http://timesofindia.indiatimes.com/india/Health-ministry-to-ask-doctors-to-writeprescriptions-in-capital-letters/articleshow/47630826.cms.

8. Bruner A, Kasdan ML. Handwriting errors: harmful, wasteful and preventable. J KY Med Associates 2001 May;99(5):189-192.

9. Farlex Partner Medical Dictionary, Farlex; 2012.

10. Miller, B., Marsh, G., \& O’Toole, M. (2003). Encyclopaedia \& dictionary of medicine, nursing, and allied health (7th ed., pp. 112-132). Philadelphia: Saunders.

11. Practice guideline and tools. Ministry of Health Singapore.

12. Four units of a university teaching hospital in Nigeria. J Public Health Epidemiol 2011;3(11):513-519.

13. Sirisha S, Thomas SM, Varghese A, Reddy R, Baby B, Gudur SP. A descriptive study on prescription audit in India - a review. Indo Am J Pharma Sci 2015;2(3):641-647.

14. Policy on safe and rational prescription of medicines of the hospital under study; 2015.

15. Albarrak AI, Al Rashidi EA, Fatani RK, Al Ageel SI, Mohammed R. Assessment of legibility and completeness of handwritten and electronic prescriptions. Saudi Pharm J 2014 Dec;26(6):522-527. 